\title{
Microwave Synthesis of Ce/BiVO 4 Nanocomposites Photocatalyst and Their Photocatalytic Properties
}

\author{
Mingcui Tuo, Shuibin Yang, Xuehong Liao* \\ Hubei Key Laboratory for Processing and Application of Catalytic Materials, The College of Chemistry and Chemical Engineering, \\ Huanggang Normal University, Huanggang, China \\ Email: *liaoxuehong@sohu.com
}

How to cite this paper: Tuo, M.C., Yang, S.B. and Liao, X.H. (2018) Microwave Synthesis of $\mathrm{Ce} / \mathrm{BiVO}_{4}$ Nanocomposites Photocatalyst and Their Photocatalytic Properties. Open Journal of Composite Materials, 8, 68-74.

https://doi.org/10.4236/ojcm.2018.82006

Received: March 16, 2018

Accepted: April 24, 2018

Published: April 27, 2018

Copyright ( $) 2018$ by authors and Scientific Research Publishing Inc. This work is licensed under the Creative Commons Attribution International License (CC BY 4.0).

http://creativecommons.org/licenses/by/4.0/

\section{Open Access}

\begin{abstract}
$\mathrm{Ce} / \mathrm{BiVO}_{4}$ nanocomposites photocatalyst was synthesized by direct feeding microwave synthesis method, using bismuth nitrate $\left(\mathrm{Bi}\left(\mathrm{NO}_{3}\right)_{3} \cdot 5 \mathrm{H}_{2} \mathrm{O}\right)$, cerium nitrate hexahydrate $\left(\mathrm{Ce}\left(\mathrm{NO}_{3}\right)_{3} \cdot 6 \mathrm{H}_{2} \mathrm{O}\right)$ and ammonium metavanadate $\left(\mathrm{NH}_{4} \mathrm{VO}_{3}\right)$ as raw material and sodium dodecyl sulfate (SDS) as surfactant. The X-ray diffractometer (XRD) and the scanning electron microscopy (SEM) technology were used to characterize the $\mathrm{Ce} / \mathrm{BiVO}_{4}$ nanocomposites. We investigated the photocatalytic activity of the as-prepared photocatalyst, and methyl orange was used as organic pollutant. The results show that the $\mathrm{Ce} / \mathrm{BiVO}_{4}$ nanocomposite was a good photocatalyst under visible light. In $100 \mathrm{ml}$ of 5 $\mathrm{mg} / \mathrm{L}$ methylene orange solution, when the catalyst calcined at $673 \mathrm{~K}$ was 0.1 $\mathrm{g}$, hydrogen peroxide was $0.5 \mathrm{ml}, \mathrm{pH}$ was 2.0 , and the degradation ratio of catalyst for methylene orange reached $90.26 \%$ within $70 \mathrm{~min}$.
\end{abstract}

\section{Keywords

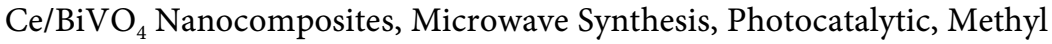 Orange}

\section{Introduction}

In recent years, haze, land pollution, water pollution and other environmental problems are becoming more and more frequent, which have been a serious threat to our survival, so we have to solve these environmental problems.

The treatment of organic wastewater is one of the hot spots. By photocatalytic degradation of organic matter and making it a harmless inorganic small molecule, it is a good green way to discharge. How to find a good photocatalyst, espe- 
cially the use of visible light or direct use of sunlight, is the focus of research. The vanadate of nanoscale is a good photocatalyst. Because of its narrow band gap, it can be used for photocatalytic degradation of organic compounds in the visible region. In particular, it can directly use sunlight, the photocatalytic degradation of organic matter [1]-[16].

In this paper, $\mathrm{Ce} / \mathrm{BiVO}_{4}$ nanocomposites photocatalyst is prepared by the method of direct feeding microwave synthesis. The samples were characterized by XRD and SEM technology. The methyl orange was used as the reactant to evaluate the photocatalytic activity of the photocatalyst.

\section{The Experiment}

\subsection{Instruments and Reagents}

Microwave oven with 650 W (Sanle General Electric Corp. Nanjing, China) was used to synthesize samples. XRD were collected on a Shimadzu XRD-6100 X-ray diffractometer $(\mathrm{Cu} \mathrm{K} \alpha$ radiation, $\lambda=0.15418 \mathrm{~nm})$. The morphology and size were characterized by SEM. he SEM images were obtained on a Quanta 200 FEG field emission scanning electron microscope. Ultraviolet-visible diffuse reflectance spectrascopy was carried out on a ShimazuUV-2600 UV-visible spectrophotometer. Lambda10 UV-vis spectrometer (Perkin-Elme Corp, USA) was used for measuring the absorption spectra on photo-degradation of methyl orange.

All the reagents were analytical purity without further purification. Ultra pure water was used throughout the experiments.

\subsection{Direct Feeding Microwave Synthesis of Ce/BiVO Nanocomposites}

$2.17 \mathrm{~g}$ of $\mathrm{Ce}\left(\mathrm{NO}_{3}\right)_{3} \cdot 6 \mathrm{H}_{2} \mathrm{O}$, and $2.42 \mathrm{~g}$ of $\mathrm{Bi}\left(\mathrm{NO}_{3}\right)_{3} \cdot 5 \mathrm{H}_{2} \mathrm{O}$ were weighed and dissolved in $50 \mathrm{ml}$ of $1 \mathrm{~mol} / \mathrm{L}$ nitric acid solution, and mixed solution a was obtained. $1.17 \mathrm{~g}$ of $\mathrm{NH}_{4} \mathrm{VO}_{3}$ was weighed and dissolved in $10 \mathrm{ml}$ of a solution containing $1 \mathrm{~mol} / \mathrm{L} \mathrm{NH}_{3} \cdot \mathrm{H}_{2} \mathrm{O}$, ultra pure water was added to $50 \mathrm{ml}$, and $1.0 \mathrm{~g}$ of SDS was added to form a solution $\mathrm{b}$ by ultrasonic dispersion. The A, B solutions were mixed rapidly transferred into $250 \mathrm{~mL}$ of flask, with $40 \%$ power (total power constant, $30 \mathrm{~s}$ work cycle, the work $12 \mathrm{~s}$, stop $18 \mathrm{~s}$ ) microwave irradiation 20 min, cool to room temperature, high speed centrifugal separation, washed with ultra pure water. The precipitate was transferred to a small beaker with acetone, at $60^{\circ} \mathrm{C}$ vacuum drying for $4 \mathrm{~h}$, and then placed in a muffle furnace and heat treated $2 \mathrm{~h}$ at different temperatures. Products collected for characterization and photocatalytic experiments.

\subsection{Photocatalytic Experiment}

Firstly, in $100 \mathrm{ml}$ of $5 \mathrm{mg} / \mathrm{L}$ methyl orange solution, the $\mathrm{pH}$ was adjusted to 2.0 with dilute nitric acid. A certain amount of $\mathrm{Ce} / \mathrm{BiVO}_{4}$ nanocomposites and 0.5 $\mathrm{ml}$ of $30 \%$ hydrogen peroxide were added, and the dispersion was uniform by ultrasonic. It was placed in the dark for 0.5 hours to reach adsorption equili- 
brium. Then, it was exposed to visible light for photocatalytic degradation experiments. A certain time interval, centrifuge separation, takes the supernatant to mensurate the absorbance. Finally, according to the change in absorbance to calculate the degradation rate of the solution, the calculation formula is as follows: $D_{t} \%=\left(A_{0}-A_{t}\right) / A_{0} \times 100 \%, A_{0}$ and $A_{t}$ is the absorbance of methyl orange before and after degradation, respectively.

\section{Results and Discussion}

Figure 1 is a XRD pattern of the sample. It Contains tetragonal zircon crystal phase $\mathrm{CeVO}_{4}$ (JCPDF NO.12-0757) and tetragonal crystal phase $\mathrm{BiVO}_{4}$ (JCPDF NO.83-1812). It can be seen that the larger the heat treatment temperature of the sample, the sharper the peak. When the calcination temperature is increased to $573 \mathrm{~K}$, the peak of sample has a very sharp, indicating the crystal growth has been very complete. According to Scherrer equation $(D=0.89 \lambda / B \cos \theta)$, we can estimate the size of the crystal. When heat treatment temperature of sample is $573,673,773 \mathrm{~K}$, the average size of as-prepared sample is $20,32.2,40 \mathrm{~nm}$, respectively.

Figure 2 is SEM image of as-prepared sample. It shows that the majority of the catalyst is a relatively nanoparticle, however, there exists obvious aggregation.

Figure 3 is the sample of UV visible diffuse reflectance spectrum. It can be seen that the reflectivity of $200-400 \mathrm{~nm}$ is below $5 \%$, and the reflectivity at 400 $600 \mathrm{~nm}$ is near $20 \%$ and the reflectivity increases rapidly at $600 \mathrm{~nm}$. Ce/BiVO nanocomposites have strong absorption in the range of visible light, which is a good photocatalyst.

Figure 4 shows the UV-Vis absorption spectra of photo-degradation of methyl orange. The $0.1 \mathrm{~g} \mathrm{Ce} / \mathrm{BiVO}_{4}$ nanocomposite calcined at $673 \mathrm{k}$ was added in the methyl orange solution of $100 \mathrm{~mL}$ with a concentration of $5 \mathrm{mg} / \mathrm{L}$ and degraded in the sunlight. It can be seen within $70 \mathrm{~min}$, the degradation rate of

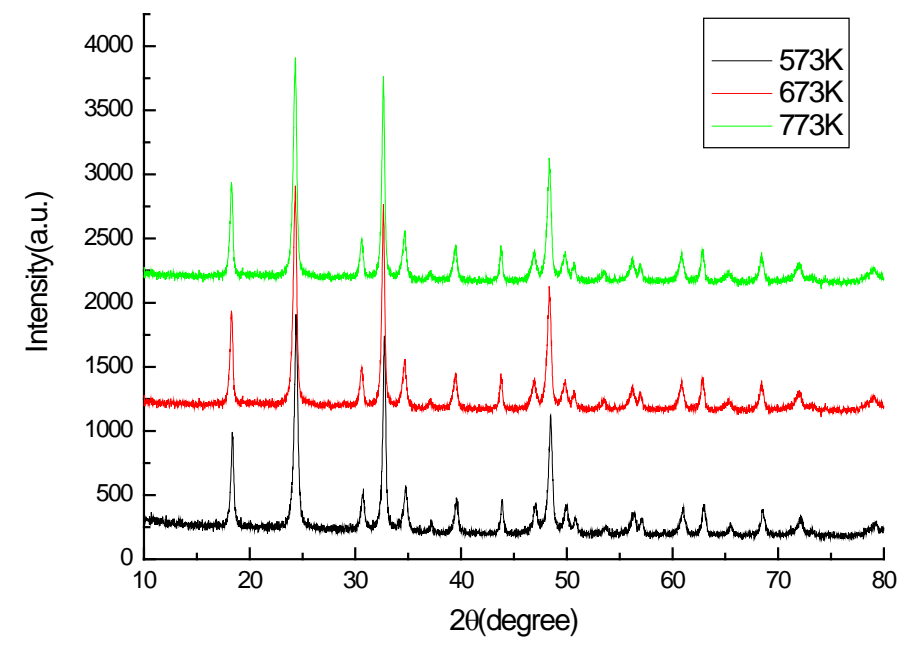

Figure 1. XRD patterns of as-prepared sample. 


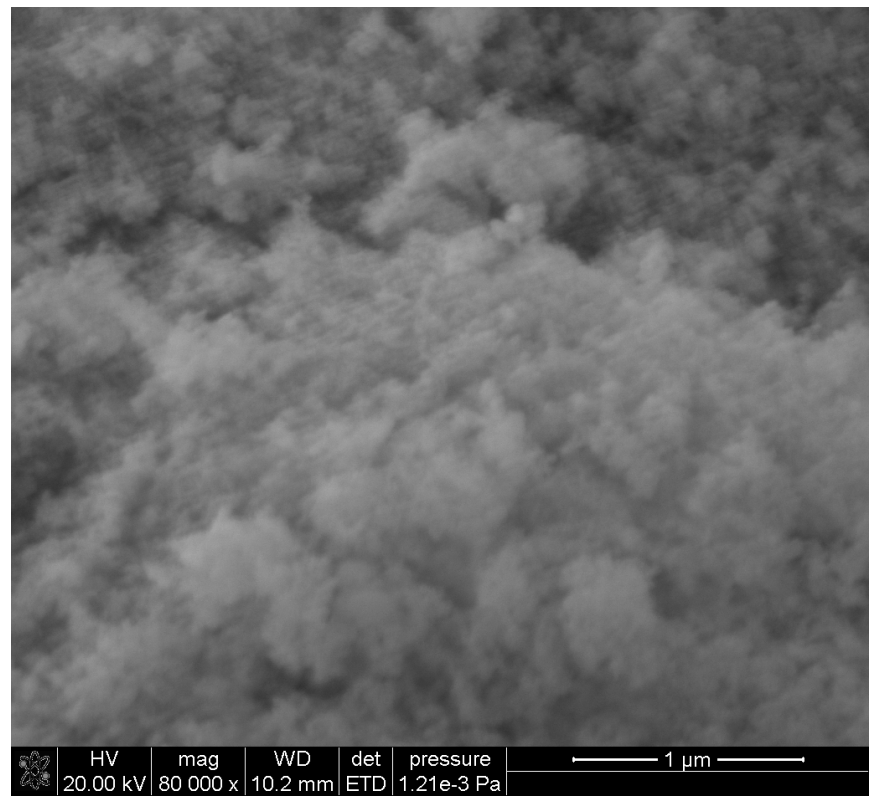

Figure 2. SEM image of as-prepared sample.

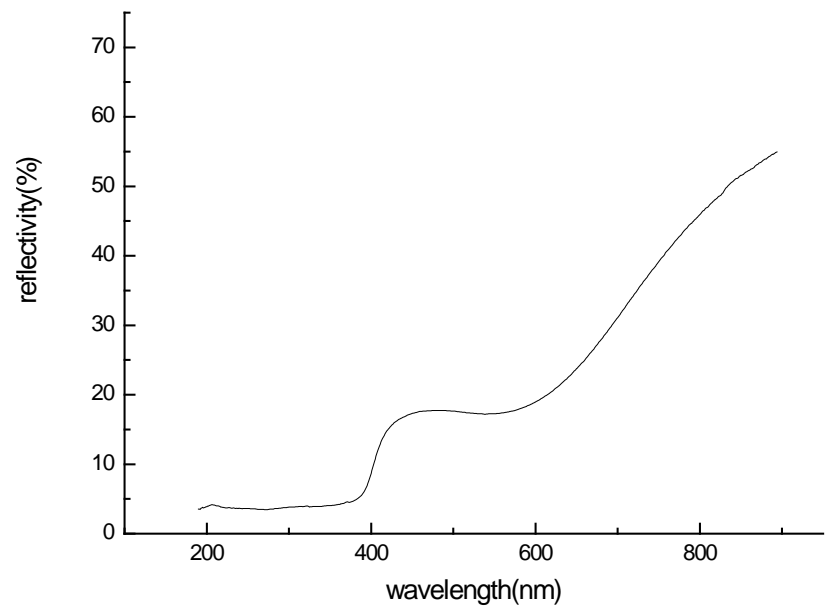

Figure 3. UV-Vis diffuse reflectance spectrum of $\mathrm{Ce} / \mathrm{BiVO}_{4}$ nanocomposite.

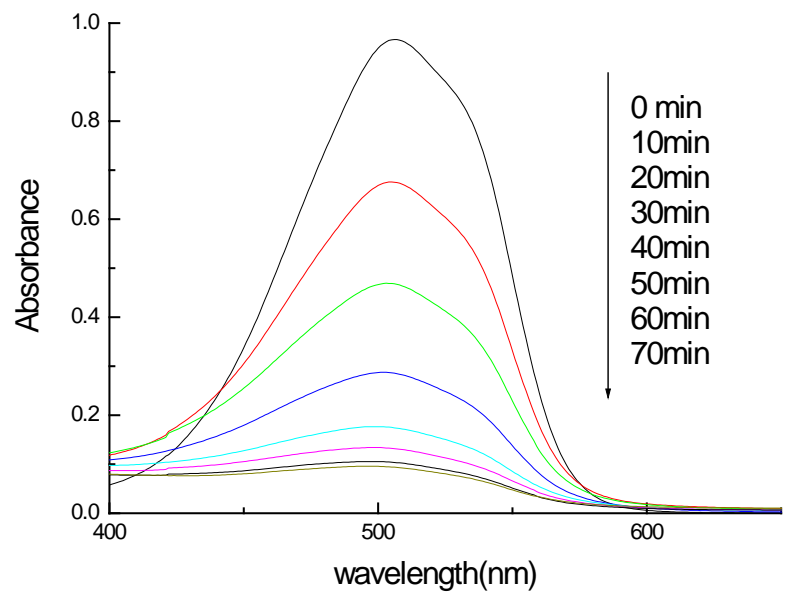

Figure 4. UV-Vis absorption spectra of photo-degradation of methyl orange. 
methyl orange solution reach $90.26 \%$. It shows that the as-prepared catalyst has good photocatalytic performance.

We also investigated the influence factors of the photocatalytic performance, such as heat treatment temperature of the catalyst (Figure 5), the load of the catalyst (Figure 6). The results show that when the heat treatment temperature is $673 \mathrm{~K}$, the load of the catalyst is about $1.5 \mathrm{~g} / \mathrm{L}$, and the photocatalytic activity of the catalyst is the best.

\section{Conclusion}

Using a direct feed microwave synthesis method, $\mathrm{Ce} / \mathrm{BiVO}_{4}$ nanocomposites have been synthesized. The results show that the $\mathrm{Ce} / \mathrm{BiVO}_{4}$ nanocomposite has excellent photocatalytic performance. In the methyl orange solution of $100 \mathrm{~mL}$ with a concentration of $5 \mathrm{mg} / \mathrm{L}$, adding $0.1 \mathrm{~g}$ of catalyst, adjusting $\mathrm{pH}$ to 2 , adding $0.5 \mathrm{~mL}$ of $30 \% \mathrm{H}_{2} \mathrm{O}_{2}$, the degradation rate could reach $90.26 \%$ in $70 \mathrm{~min}$ under sunlight.

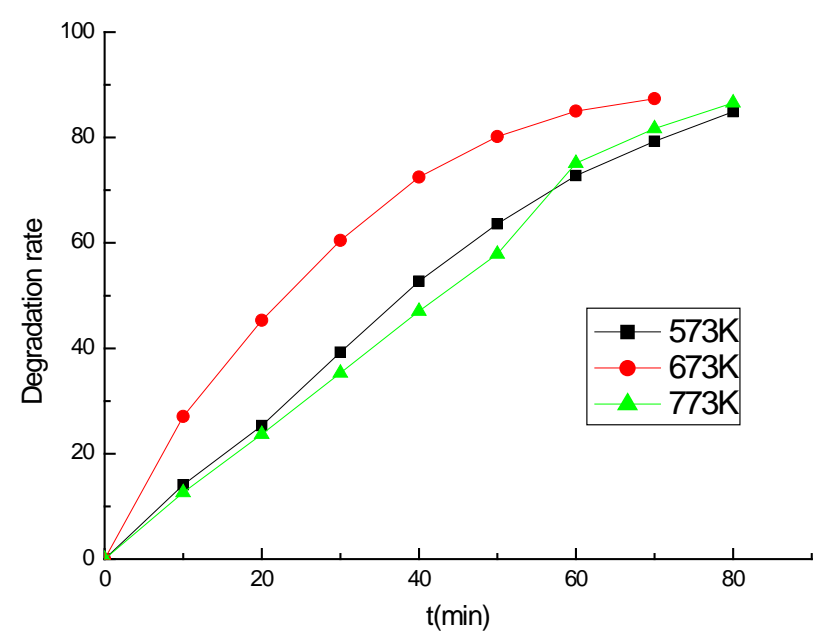

Figure 5. Affect of different heat treatment temperature on photocatalytic activity.

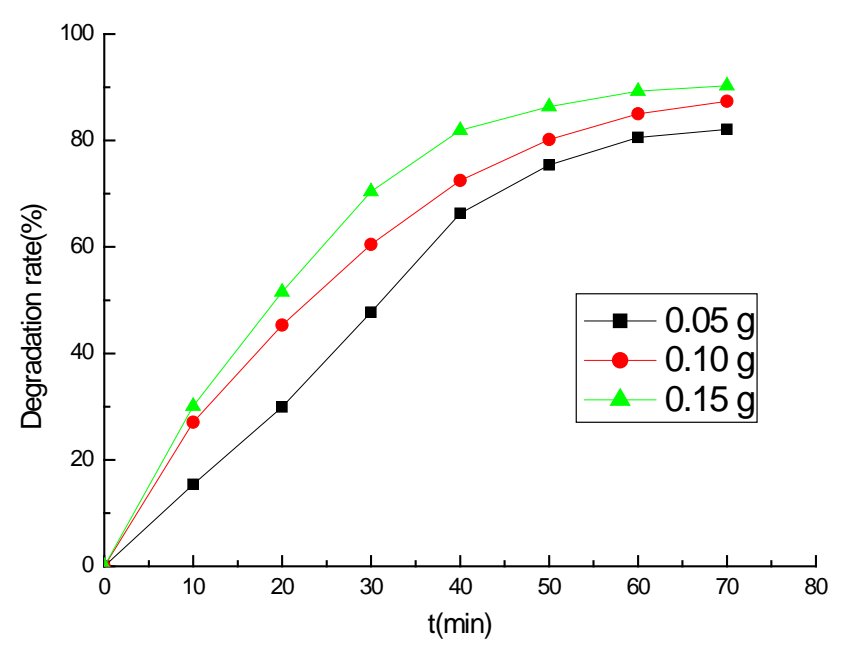

Figure 6. Affect of load of catalyst on photocatalytic activity. 


\section{References}

[1] Min, Y.L., Zhang, K., Chen, Y.C. and Zhang, Y.G. (2012) Sonodegradation and Photo Degradation of Methyl Orange by $\mathrm{InVO}_{4} / \mathrm{TiO}_{2}$ Nanojunction Particles under Ultrasonic and Visible Light Irradiation. Ultrasonics Sonochemistry, 19, 883-889. https://doi.org/10.1016/j.ultsonch.2011.12.015

[2] Wang, J.X., Ruan, H., Li, W.J., et al. (2012) Highly Efficient Oxidation of Gaseous Benzene on Novel $\mathrm{Ag}_{3} \mathrm{VO}_{4} / \mathrm{TiO}_{2}$ Nanocomposite Photocatalysts under Visible and Simulated Solar Light Irradiation. The Journal of Physical Chemistry C, 116, 13935-13943. https://doi.org/10.1021/jp301355q

[3] Wetchakun, N., Chaiwichain, S., Inceesungvorn, B., et al. (2012) $\mathrm{BiVO}_{4} / \mathrm{CeO}_{2} \mathrm{Na}-$ nocomposites with High Visible-Light-Induced Photocatalytic Activity. ACS Applied Materials \& Interfaces, 4, 3718-3723. https://doi.org/10.1021/am300812n

[4] Lu, Y., Luo, Y.S., Kong, D.Z., et al. (2012) Large-Scale Control Lable Synthesis Is of Dumbbell-Like $\mathrm{BiVO}_{4}$ Photocatalysts with Enhanced Visible-Light Photocatalytic Activity. Journal of Solid State Chemistry, 186, 255-260.

https://doi.org/10.1016/j.jssc.2011.12.003

[5] Nithya, V.D., Kalai Selvan, R., Sanjeeviraja, C., et al. (2011) Synthesis and Characterization of $\mathrm{FeVO}_{4}$ Nanoparticles. Materials Research Bulletin, 46, 1654-1658. https://doi.org/10.1016/j.materresbull.2011.06.005

[6] Deshpande, P.A. and Madras, G. (2010) Photocatalytic Degradation of Phenol by Base Metal-Substituted Orthovanadates. Chemical Engineering Journal, 161, 136-145. https://doi.org/10.1016/j.materresbull.2011.06.005

[7] Rakesh, K., Khaire, S., Bhange, D., et al. (2011) Role of Doping-Induced Photochemical and Microstructural Properties in the Photocatalytic Activity of $\mathrm{InVO}_{4}$ for Splitting of Water. Journal of Materials Science, 46, 5466-5476.

https://doi.org/10.1007/s10853-011-5489-5

[8] Li, T.T., Zhao, L.H., He, Y.M., et al. (2013) Synthesis of g- $\mathrm{C}_{3} \mathrm{~N}_{4} / \mathrm{SmVO}_{4}$ Composite Photocatalyst with Improved Visible Light Photocatalytic Activities in RhB Degradation. Applied Catalysis B: Environmental, 129, 255-263. https://doi.org/10.1016/j.apcatb.2012.09.031

[9] $\mathrm{Xu}$, J., Hu, C.G., Liu, G.B., et al. (2011) Synthesis and Visible-Light Photocatalytic Activity of $\mathrm{NdVO}_{4}$ Nanowires. Journal of Alloys and Compounds, 509, 7968-7972. https://doi.org/10.1016/j.jallcom.2011.05.051

[10] Yao, W. F., Iwai, H. and Ye, J.H. (2008) Effects of Molybdenum Substitution on the Photocatalytic Behavior of $\mathrm{BiVO}_{4}$. Dalton Transactions, 11, 1426-1430. https://doi.org/10.1039/b713338c

[11] Eda, S., Fujishima, M. and Tada, H. (2012) Low Temperature-Synthesis of $\mathrm{BiVO}_{4}$ Nanorods Using Polyethylene Glycol as a Soft Template and the Visible-Light-Activity for Copper Acetylacetonate Decomposition. Applied Catalysis B: Environmental, 125, 288-293. https://doi.org/10.1016/j.apcatb.2012.05.038

[12] Sun, W.T., Xie, M.Z., Jing, L.Q., et al. (2011) Synthesis of Large Surface Area Nano-Sized $\mathrm{BiVO}_{4}$ by an EDTA-Modified Hydrothermal Process and Its Enhanced Visible Photocatalytic Activity. Journal of Solid State Chemistry, 184, 3050-3054. https://doi.org/10.1016/j.jssc.2011.09.013

[13] Iwase, A. and Kudo, A. (2010) Photoelectrochemical Water Splitting Using Visible-Light-Responsive $\mathrm{BiVO}_{4}$ Fine Particles Prepared in an Aqueous Acetic Acid Solution. Journal of Materials Chemistry, 20, 7536-7542.

https://doi.org/10.1016/j.jssc.2011.09.013 
[14] Sun, Y.F., Qu, B.Y., Liu, Q.S., et al. (2012) Highly Efficient Visible-Light-Driven Photocatalytic Activities in Synthetic Ordered Monoclinic $\mathrm{BiVO}_{4}$ Quantum Tubes-Graphene Nanocomposites. Nanoscale, 4, 3761-3767.

https://doi.org/10.1039/c2nr30371j

[15] Chen, L., Yin, S.F., Huang, R., et al. (2012) Hollow Peanut-Like m-BiVO 4 : Facile Synthesis and Solar-Light-Induced Photocatalytic Property. CrystEngComm, 14, 4217-4222. https://doi.org/10.1039/c2ce06684j

[16] Xie, B.P., Zhang, H.X., Cai, P.X., et al. (2006) Simultaneous Photocatalytic Reduction of $\mathrm{Cr}$ (VI) and Oxidation of Phenol Over Monoclinic $\mathrm{BiVO}_{4}$ under Visible Light Irradiation. Chemosphere, 63, 956-963.

https://doi.org/10.1016/j.chemosphere.2005.08.064 